Service social

\title{
Soins infirmiers interculturels. Recueils de données et actions de soins, par Joyce Newman Giger et Ruth Elaine Davidhizar, Boucherville, Gaëtan Morin éditeur, 1991, 308 pages.
}

\section{Raymonde Giordani}

Volume 41, numéro 3, 1992

Intervenir en contexte d'autorité

URI : https://id.erudit.org/iderudit/706594ar

DOI : https://doi.org/10.7202/706594ar

Aller au sommaire du numéro

Éditeur(s)

École de service social de l'Université Laval

ISSN

1708-1734 (numérique)

Découvrir la revue

Citer ce compte rendu

Giordani, R. (1992). Compte rendu de [Soins infirmiers interculturels. Recueils de données et actions de soins, par Joyce Newman Giger et Ruth Elaine Davidhizar, Boucherville, Gaëtan Morin éditeur, 1991, 308 pages.] Service social, 41(3),

137-139. https://doi.org/10.7202/706594ar d'utilisation que vous pouvez consulter en ligne.

https://apropos.erudit.org/fr/usagers/politique-dutilisation/ 


\title{
SOINS INFIRMIERS INTERCULTURELS. RECUEILS DE DONNÉES ET ACTIONS DE SOINS
}

\author{
Joyce Newman Giger et Ruth Elaine Davidhizar,
} Boucherville, Gaëtan Morin éditeur, 1991, 308 pages.

Ces dernières années, le phénomène de l'immigration et les contacts culturels entre les groupes humains les plus divers qui en découlent deviennent un propos central dans les sociétés occidentales. Le pluralisme culturel engendré par la présence de l'Autre, dans des vies qui se réclamaient jusqu'ici d'une même identité, a créé des remous dont certaines disciplines scientifiques, I'anthropologie par exemple, nous ont entretenus depuis longtemps.

Depuis une dizaine d'années environ, le domaine des soins infirmiers, entraîné dans cette interrogation, cherche, lui aussi, à gérer cette diversité culturelle par la promotion de soins infirmiers culturellement adaptés, c'està-dire de soins qui tiendraient compte de la culture particulière dont chaque patient est porteur. Le livre de Giger et Davidhizar se situe parfaitement dans le cadre de ces préoccupations. Le concept central de l'ouvrage est celui de soins infirmiers interculturels. Il sert d'élément charnière autour duquel se tissent, serrés et constants, les liens entre les concepts de soins et de culture. Giger et Davidhizar, deux Américaines, abordent cette problématique dans un contexte d'enseignement en soins infirmiers et font face à la difficulté de faire saisir à des étudiants appartenant à une discipline non apparentée aux sciences sociales comment "fonctionne », dans la pratique, un concept comme celui de culture. De là leur est venue l'idée de relever le défi de créer une approche systématique qui vise à compenser le manque d'outils pratiques et qui permet au personnel soignant de reconnaître et de recueillir les variables culturelles influençant les comportements de santé et de maladie.

Leur ouvrage est présenté dans une excellente traduction française. II se divise en deux parties. La première décrit de manière concrète l'utilisation de la méthode proposée et permet de mettre en évidence, à travers six « phénomènes culturels » qui ont la propriété commune d'être présents dans toutes les cultures, les liens qui existent entre les soins et la culture. Il y est question de modes de communication, de l'utilisation de l'espace, de la perception du temps, de l'organisation sociale, de la perception et de la gestion de l'environnement, des variations biologiques et des liens qu'entretient chacun de ces six "phénomènes culturels » avec le recueil des données.

L'ouvrage a été élaboré dans le souci d'augmenter l'aptitude des soignants à déceler et à composer avec les conséquences du contact culturel tant pour le patient que pour le thérapeute. Chaque « phénomène culturel » fait donc l'objet d'un chapitre propre et est abordé sous plusieurs angles. En premier lieu, les objectifs comportementaux visés chez les étudiants sont définis. Puis, Giger et Davidhizar explorent certaines dimensions essentielles du phénomène culturel décrit. Les auteures abordent ensuite l'illustration de la variabilité culturelle à l'aide de nombreux exemples puisés dans la 
mosaïque culturelle de la société américaine. Prennent alors place les conséquences intéressant la vie quotidienne du personnel soignant, présentées sous forme de décisions pratiques. Chaque chapitre est enfin clos par une étude de cas, des questions à l'étude et des références bibliographiques appropriées.

La deuxième partie du livre se compose, dans l'édition française, d'un unique chapitre d'illustration de la méthode proposée. On y fait connaissance avec le groupe culturel juif américain. L'édition américaine, pour sa part, en compte quatorze, chacun s'intéressant à autant de groupes ethniques présents dans la société américaine. Ici encore, d'entrée de jeu, sept objectifs comportementaux rappellent la vocation didactique de l'ouvrage. Un survol historique permet ensuite de caractériser les trois vagues d'immigration qui expliquent, selon les auteures, la culture juive américaine d'aujourd'hui. Enfin, chacun des « phénomènes culturels » est peint avec la coloration propre que lui confère la communauté juive américaine. Les conséquences pratiques qui touchent les soins à offrir aux patients appartenant à cette communauté sont clairement soulignées. Comme dans la première partie de l'ouvrage, études de cas, questions assorties et références bibliographiques s'enchaînent pour clore le chapitre et la deuxième partie.

Bien que les auteures aient été formées en soins infirmiers et que « ce livre [ait] été écrit à l'intention de toutes les infirmières et étudiantes infirmières » (p. 23), elles ont réussi à nous éclairer sur l'importance et les conséquences pratiques, dans la vie quotidienne comme dans les situations de soins, des six phénomènes culturels retenus comme manière d'aborder le vécu culturel propre à chaque patient. De ce fait, les disciplines scientifiques qui placent les relations des êtres humains entre eux et avec leur environnement au centre de leurs préoccupations sont bien servies. Et, à la lecture de cet ouvrage, étudiants et chercheurs appréhendent un être humain porteur d'une histoire, de dimensions ethnologique et biologique qui le lient à une communauté particulière, mais reconnaissent aussi un être unique et singulier au sein même de son groupe d'appartenance.

Par ailleurs, Giger et Davidhizar admettent que « pour comprendre les soins infirmiers interculturels et leurs implications pour les soins infirmiers, il faut avoir des connaissances de base sur la culture, les valeurs culturelles et la diversité culturelle des soins infirmiers » (p. 28). Pourtant, elles font l'économie d'un certain encadrement théorique. Ces concepts, empruntés en bonne partie aux sciences sociales, sont offerts en un paragraphe succinct où ne figurent que les seules définitions proposées par Madeleine Leininger (qui fait figure de sommité, mais en soins infirmiers transculturels seulement). De plus, la simple définition du concept de soins infirmiers interculturels apparaît absolument insuffisante pour rendre compte de la problématique complexe du contact culturel et de ses conséquences. La personne qui veut évoluer avec un maximum de profit dans cette lecture doit s'être familiarisée avec ces concepts et être à l'aise dans cette problématique. 
Cependant, I'ouvrage reste un outil précieux pour tous ceux et celles qui ont pour objectif de créer une sensibilité nouvelle, plus ouverte, plus indulgente au phénomène de cohabitation culturelle. II n'atteindra toutefois son plein objectif qu'à deux conditions : la première sera le souci, chez les enseignants du Québec, d'adapter à la réalité québécoise les exemples proposés pour le lecteur américain. Ensuite, si ce livre est destiné à des étudiants de premier cycle et si, de surcroît, ils appartiennent à une discipline non apparentée aux sciences sociales, un effort d'enrichissement de certains concepts de base devra être consenti, afin que les étudiants visés tirent le maximum de cette indispensable contribution.

Raymonde GIORDANI

École des sciences infirmières

Université Laval 